\title{
The Art of Film and Television Packing
}

\author{
Lun Yang \\ Wuhan Textile University School of Media and Communication Hubei Wuhan \\ 405908259@qq.com
}

Keywords: Film packaging; Elements; Creation; Art performance

\begin{abstract}
The nods eyeball pen of film packaging as a film, it is important for the whole movie style to produce. Film packaging is a kind of art design with film properties and thinking space form of art. Art of film and television packaging, and other art creation, its charm is the perfect unification of content and form of expression. Elements of film and television packing, involving the picture element layout, the screen brightness and chromaticity relationship, character design and so on. Film packaging creation, also should consider the integrated use of film and television packing element, packaging film and TV packaging visual differences and the audience's feelings.
\end{abstract}

\section{The Concept of Film Packaging and Process}

Film theorists marla's once said: "the birth of film art not only creates new works of art, but also makes the human to get a new ability, is used to understand and experience the new art." In current society, film and television art is backed by science and technology, collect a variety of artistic essence of art form, is the most dynamic and influential comprehensive art, there is a broad mass base of popular art types. Video art has become such a popular main contents and important form of publicity and entertainment. The film and television works has the characteristics of to emotional person, osmosis, recreation, has played a huge role in social life.

The Concept of Film Packaging. Film packaging is based on the theory of visual communication design, is to use video editing equipment and video editing skills, make the film and television special effects on technology; Is a producer of film and television works late for the film and television works the overall image of the specification and strengthening of the external form elements. Forms of external factors including the sound (language, sound, music and sound effects, etc.), image (fixed frame, motion pictures, animations,) the essential elements, color, etc, and is the theme of the film content accurately modelling the nods eyeball pen of rhythm concentrated expression on the screen. With the wide application of high and new technology in the field of film and television production, film and television packing art qualitative leap. Through technical means to wrap film and television creative and conception, color and lighting, composition and form, music and other art elements together, constitute a harmonious unified whole, achieve the perfect combination of art and technology, the greatest extent to meet the aesthetic needs of audience of the film and television works.

Film packaging earlier is for movies, TV, or at the beginning of the used to build momentum, foil show products names, production unit, a video material information. With the popularity of computer, especially the development of multimedia technology, the application scope of now himself through the opening extends to the trailer, until the end, subtitles, etc. In the film due to the opening of the audience is the first impression, it learned to overall shows the style of the film and television works and imposing manner, showing the level and quality of work, so the production of film and television packing has a very important influence on the whole film and television works.

\section{Elements of Film and Television Packing}

Art of film and television packaging, and other art creation, its charm is the perfect unification of content and form of expression. To achieve the desired effect of the film and television packing, according to the different theme of the film, different style, different content, design the different solutions and different forms. 
Film packaging design is different from general art design, it is not an independent design work, but through the implementation of all sorts of modelling design on the screen, the screen conforms to the audience aesthetic habit, reflects the central idea of film. Creation of film and television packing the restriction of the film and television program content, its creation must comply with the regulations of film and television shows characteristics of The Times and the characteristics of national geographic. The visual effect of image by everyone of their own culture and interests, not a given. The creation of the film and television packing, however, has its basic elements.

The Layout of the Picture Element. In film and television packing picture, the line is being frequently used visual elements to use, appropriate use of lines will win the attention of the audience. Even on all visual elements can be summed up in a line, they guide the audience's attention. Audience will always pay special attention to the intersection of line or line change seats, the film "die hard" end is designed using the line in a three-dimensional space lengthen, evolved into a variety of characters, the audience always follow line is constantly moving, the line of sight of the last line of sight to gather on the images of characters.

Is not a good picture layout techniques that can easily portrayed in the drawing, but from the experience of success and failure. Although just into the beginners can come into contact with a large number of technical description on design work, but about the layout of the picture, the core of the visual communication skills, is considered a kind of hard to depict the talent and without explanation. Is popular in Western Europe, the art of design in another way, they think that the layout of the picture is a kind of intuition, and this feeling is meaningless. Sound reinforce the message, but the picture layout design determines the current picture how will be the audience to understand. So the picture should use simple and direct way to convey information. Good packing staff will set up visual elements, to express a clear information, good picture layout can promote brain understanding of information. Production of film and television packing must provide a designed route to direct the eye movement on the screen, to help the audience to understand the picture conveys information. Eye movement should be continuous, smooth, and along the path has been designed in advance on the pictures and other related movement between elements, and won't be misled into the picture is not important visual elements.

Image is balanced, affecting the film and television screen layout and composition of the reasonable and perfect. Color is harmonious, modelling is beautiful, it can be said that the picture composition design, the most important thing is that the layout of the equilibrium. We also note that because the "move" is the main characteristics of film and television picture, thus has and static images in the treatment of different places, various visual elements in the picture all can affect the balance of picture. Equilibrium is shall abide by the laws in most case, but cannot deny the existence of unbalanced art because of this, sometimes to make a special picture, we can often deliberately to violation of the laws of equilibrium.

Screen Bightness and Cromaticity Rlations. Lightness and images of light and shade relations, chromaticity and picture of the color relations, the relationship of color in the picture provided their balance, contrast, rhythm, structure, texture, and depth, and independent of any possible in lines or composition of the basic visual elements. In many creative film packaging, color not only has a profound influence on the image, and even sometimes is the body of the picture.

Colour is often associated with emotion, the film and television colour in the packaging is the product of fashion and culture, but also part of the performance for the express information. According to the west now colour preference sequence of video images, followed by, blue, yellow, orange, green. This order is constantly changing of course, the first condition of choosing color is to be in conformity with the main content of the film. The film "the omen" opening design using the dark red background and red font, suggests that the film content related to religious belief.

Each element has a certain brightness of the image, the image on the difference between light and shade to give a person with the administrative levels feeling on the vision. This kind of visual sense, depend on organization relationship between adjacent objects, the size and contrast of light and dark areas. The line of sight of people in front of the screen, naturally attracted by high brightness area, but high brightness of the image part must be set up on the contrast, with adjacent 
object that is to pull level. The relationship between the different brightness levels for images of light and shade information ability is very important. On opening picture processing, the contrast of light and shade relations deliberately weakened to create a new visual effect, the movie the Hollywood boulevard opening design, use the famous Hollywood sign as the title, fuzzy black-and-white picture effect caused psychological distress to the audience.

\section{Conclusion}

A perfect film packaging design is the style of the film and television creative performance of interpretation, it by technical means for the audience to its meaning and resonance, so as to impress. Film packaging is the modelling of the film and television theme and content accurate rhythm concentrated expression in the nods eyeball pen of the screen. Creativity as the soul of the whole package, is the core of the film and television packing, only do novel idea, unique, let a person never forgets anything, in order to stand out in the numerous film and television works. In order to make the film become shiny silver screen art first "a", the designer to understand the basic elements, thoroughly grasp the design principles, good at thinking and innovation, effectively solve the visual vigor and the essence of life emotional contact, to get rich in artistic creation to the vast number of visual art convey film and TV viewers, constantly meet people's growing spiritual and cultural needs.

\section{References}

[1] Stanford. Analyze the expression of film and television visual elements in the design of analysis [J]. Beijing: the movie literature. 2008.10

[2] Zhou. Hollywood revelation [M]. Shanghai: Fudan university press, 2005.5

[3] Meg. 20th century history of visual communication design [M]. Wuhan: Hubei fine arts publishing house. 1994. N

[4] Iang Xun. Introduction to art [M]. Beijing: sanlian publishing house, 2000.6

[5] Pan's base. The meaning of visual art [M]. Shenyang: liaoning people's publishing house. 1987.8

[6] Jacques Lang Dewei \& Denis Linton. The principles of marketing [M] Economic science press.2000.

[7] Cai Shangwei. Media and popular culture [M]. Sichuan university press. 2005.

[8] Ye Jianxin, Liu Daxuan, Zhang Guozhen. TV art introduction [M]. China radio and television publishing house. 2002.

[9] Fang Haishan. Film and television production wonderful case analysis [M]. China electric power press. 2005.

[10] Money home. Visual psychology [M]. Beijing: Stanford university press. 2006.6 